\title{
Влияние ионной подсистемы на термоэлектрический эффект в коллоидных растворах
}

\author{
(C) А.В. Сидоров ${ }^{1}$, В.М. Грабов ${ }^{2}$, А.А. Зайцев ${ }^{1}$, Д.В. Кузнецов ${ }^{1}$ \\ ${ }^{1}$ Елецкий государственный университет им. И.А. Бунина, \\ 399770 Елец, Россия \\ ${ }^{2}$ Российский государственный университет им. А.И. Герцена, \\ 191186 Санкт-Петербург, Россия \\ E-mail: dirnusir@mail.ru
}

Поступила в Редакцию 20 октября 2021 г.

В окончательной редакции 25 октября 2021 г.

Принята к публикации 25 октября 2021 г.

\begin{abstract}
Исследован термоэлектрический эффект в смесях коллоидных растворов с ионными электролитами в начальном состоянии, когда формированием градиентов концентрации под влиянием неоднородного температурного поля можно пренебречь. На основе экспериментальных измерений в смесях с различной концентрацией коллоидных частиц и ионов определены условия, при которых коэффициент термоэлектрической эдс коллоидного раствора определяется ионной подсистемой, а при каких главный вклад в величину термоэлектрической силы вносят коллоидные частицы.
\end{abstract}

Ключевые слова: коллоидный раствор, термоэлектрический эффект, ионная подсистема.

DOI: $10.21883 /$ FTP.2022.02.51959.32

\section{1. Введение}

Термоэлектрический эффект в растворах электролитов был открыт позже, чем в твердых телах, в конце XIX века. Он получил детальное описание в рамках феноменологической теории необратимых процессов только в середине XX века. Если в твердотельных средах при наблюдении и измерении явления Зеебека присутствуют только контакты двух разных металлов или полупроводников [1], на которых образуется падение электрического потенциала вследствие перераспределения электронов между проводниками, то в жидких растворах электролитов, кроме контакта двух разных жидкостей, обязательно присутствуют границы раздела фаз твердое тело-жидкость [2], через которые происходит транспорт ионов и на которых происходят окислительновосстановительные химические реакции. Поэтому в растворах электролитов итоговая разность термоэлектрических потенциалов складывается из падения потенциала на границе металлический электрод-раствор электролита, и падения потенциала внутри жидкости, находящейся в неоднородном температурном поле.

Первоначально интерес к термоэлектрическим явлениям в растворах электролитов был теоретическим, так как измерения величины термоэлектрической эдс позволяли определить такие характеристики ионов, как теплоты $Q_{i}$ и энтропии переноса $S_{i}$. Однако в последнее время практический интерес к данным явлениям возрос в связи с перспективами создания на их основе термоэлектрохимических ячеек - экологически чистых, возобновляемых источников электрической энергии [3-5]. Итоговая величина эдс в таких устройствах, как уже было отмечено ранее, складывается из падения потенциала на границе твердотельных электродов и жидкого раствора и вклада, образующегося внутри жидкого электролита, на который наложено неоднородное температурное поле.

В нашей работе исследуется гомогенный вклад, обусловленный термодиффузионными процессами внутри электролита. Выражение для градиента электрического потенциала в этом случае может быть получено в рамках термодинамики необратимых процессов [6]:

$$
\operatorname{grad}(\varphi)=\frac{1}{\mathrm{~F}} \frac{\sum_{i, k} z_{i} a_{i k}}{\sum_{i, k} z_{i} z_{k} a_{i k}}\left[-\operatorname{grad}\left(\mu_{k}\right)-\frac{Q_{k}^{*}}{T} \operatorname{grad}(T)\right] .
$$

Здесь введены следующие обозначения: $\varphi$ - электрический потенциал, F - постоянная Фарадея, $z_{i}-$ заряд ионов электролита в единицах заряда электрона, $a_{i k}$ - феноменологические коэффициенты, $\mu_{k}-$ химический потенциал частиц электролита, $T-$ абсолютная температура, $Q_{k}^{*}$ - теплота переноса частиц вида $k$. Феноменологические коэффициенты могут быть выражены через так называемые приведенные числа переноса ионов $\tau_{k}$ :

$$
\frac{\sum_{i} z_{i} a_{i k}}{\sum_{i} z_{i} z_{k} a_{i k}}=\tau_{k} .
$$

Данные величины численно равны относительной доле потока частиц вида $k$, который они вносят в суммарный электрический ток в электролите. Приведенные числа переноса также могут быть выражены через концентрации частиц $c_{k}$, их подвижности $u_{k}$ и электрический заряд:

$$
\tau_{k}=\frac{c_{k} u_{k}}{\sum_{k}\left|z_{k}\right| c_{k} u_{k}} .
$$


Таким образом, в растворе электролита будет возникать внутреннее электрическое поле, которое в начальные моменты времени, когда градиенты концентрации еще не сформировались, будет определяться следующим выражением:

$$
\operatorname{grad}\left(\varphi_{0}\right)=-\frac{1}{\mathrm{~F}} \sum_{k} \tau_{k} Q_{k}^{*} \frac{\operatorname{grad}(T)}{T} .
$$

Данный потенциал $\varphi_{0}$ в литературе называют термодиффузионным потенциалом в узком смысле [6]. Спустя некоторое время за счет явления термодиффузии в растворе возникнет градиент концентрации ионов, который вызовет возникновение потенциала диффузии, который совместно с потенциалом термодиффузии в узком смысле называют потенциалом термодиффузии в широком смысле.

Из выражения (4) видно, что величина разности термоэлектрических потенциалов в начальном состоянии пропорциональна перепаду температуры, поэтому по аналогии с твердотельными средами коэффициент пропорциональности между разностями электрического потенциала и температуры может быть назван коэффициентом термоэдс электролита в начальном состоянии

$$
\alpha_{0}=-\frac{1}{\mathrm{~F}} \sum_{k} \frac{\tau_{k} Q_{k}^{*}}{T} .
$$

Как следует из выражения (5), его величина определяется соотношением между числами переноса и теплотами переноса заряженных частиц раствора. Из исследования явления термодиффузии в коллоидных растворах известно, что теплота переноса коллоидных частиц на несколько порядков превышает теплоту переноса индивидуальных ионов, что обусловлено, в частности, их крупными размерами $[7,8]$, также было обнаружено, что коэффициент термоэдс некоторых коллоидных растворов имеет большую величину [9]. Поэтому можно предположить, что присутствие коллоидных частиц в растворе электролита может повысить его коэффициент термоэдс и тем самым термоэлектрическую эффективность термоэлектрохимических ячеек.

Соответственно цель нашей работы заключается в исследовании взаимного влияния присутствия коллоидных частиц и ионов на итоговую величину термоэлектрической эдс коллоидных растворов.

\section{2. Описание методики эксперимента}

Коэффициент термоэлектрической эдс в работе определялся с помощью следующей экспериментальной установки (рис. 1).

Исследуемый раствор 2 заливался в U-образную трубку 1 , одно из колен которой нагревалось электрическим нагревателем 3. В качестве измерительных электродов 6 использовались хлорсеребряные электроды, в которых

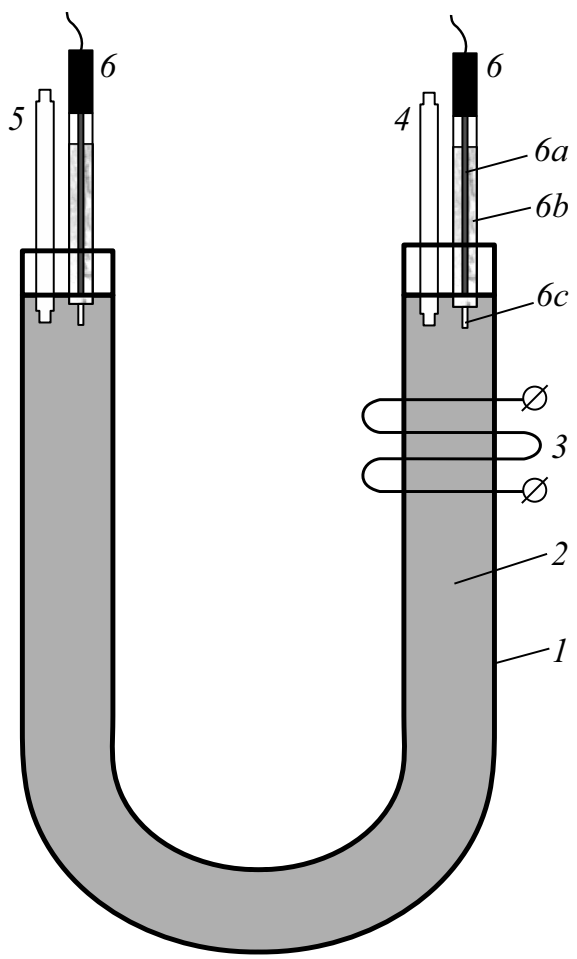

Рис. 1. Схема экспериментальной установки для измерения коэффициента термоэлектрической эдс в растворах электролитов.

металлическая проволока, покрытая нерастворимой солью хлорида серебра помещалась в стеклянном корпусе, в который заливался насыщенный раствор хлористого калия.

В нижней части корпус имеет небольшие отверстия (электролитические ключи), благодаря которым электроды контактируют с исследуемым раствором. Температура в нагреваемой и холодной областях электролита регистрируется терморезистором 4 и термометром 5 . При измерении термоэлектрической эдс электролитические ключи электродов находятся вблизи верхней границы растворов, поэтому в момент начала повышения температуры в нагреваемой области жидкости между измерительными электродами возникает разность термоэлектрических потенциалов $\Delta \varphi_{0}$, выражение для которой было приведено ранее (4). Лишь спустя некоторое время должна начать заметно повышаться температура приэлектродного раствора $6 b$ и самого электрода $6 a$ и в регистрируемом сигнале должна появиться составляющая, обусловленная неравенством температур однотипных хлорсеребряных электродов. Это действительно подтверждается в эксперименте [10]. Таким образом, в данной экспериментальной установке регистрируется именно разность термоэлектрических потенциалов, соответствующая начальному состоянию, из которой может быть определен коэффициент термоэдс $\alpha_{0}$. 


\section{3. Экспериментальные результаты и обсуждение}

С использованием данной методики были получены концентрационные зависимости коэффициента термоэдс для смесей коллоидных растворов с ионными электролитами (рис. 2 и 3 ).

В первом случае (рис. 2) исследовалось изменение коэффициента термоэлектрической эдс смеси $2 \%$ коллоидного раствора канифоли с ионным электролитом $\mathrm{NaOH}$ для различных концентраций $\mathrm{NaOH}$. Там же на рисунке показана концентрационная зависимость для беспримесного $\mathrm{NaOH}$. Результаты показывают, что при относительно высоком содержании ионного электролита в смеси ее коэффициент термоэдс в пределах погрешности эксперимента совпадает с коэффициентом термоэдс беспримесного ионного электролита той же концентрации. При уменьшении относительного содержания ионного электролита коэффициент термоэдс смеси стремится к значению для беспримесного коллоидного раствора.

Аналогичный вывод следует и из анализа коэффициента термоэдс смеси коллоидного раствора танина и хлорида олова (рис. 3). Похожие результаты, но в смесях коллоидного раствора крахмала с различными электролитами, наблюдались в работе [11].

Полученный результат, очевидно, может быть объяснен уменьшением вклада в итоговый коэффициент термоэдс ионов и увеличением вклада коллоидных частиц вследствие уменьшения чисел переноса ионов и увеличения чисел переноса коллоидных частиц (5) при изменении их концентраций в смеси в соответствии с выражением (3).

Изменить соотношение между концентрациями свободных ионов и коллоидных частиц в смеси можно также, удаляя ионы из раствора с помощью метода диализной очистки [12]. Метод основан на свойстве полупроницаемых мембран пропускать мелкие ионы и задерживать крупные коллоидные частицы. В качестве такой мембраны в работе использовалась целлюлозная оболочка, в которую заливался исследуемый раствор. Оболочка помещалась в сосуд с дистиллированной водой. Процесс диализа контролировался по измерению электропроводности очищаемого раствора и воды в сосуде. Когда их электропроводности сравнивались, коллоидный раствор заливался в новую оболочку, которая помещалась в следующую порцию дистиллированной воды.

Таким образом, было исследовано изменение коэффициента термоэлектрической эдс коллоидного раствора иодида серебра в процессе его диализной очистки. Коллоидный раствор получался в результате реакции двойного обмена $\mathrm{AgNO}_{3}+\mathrm{KI}=\mathrm{AgI}+\mathrm{KNO}_{3}$. Поэтому он представлял собой смесь коллоидных частиц иодида серебра и ионного компонента - нитрата калия. Реакция проводилась с избытком иодида калия, вследствие чего частицы иодида серебра заряжались отрицательно из-за адсорбции из раствора ионов $\mathrm{I}^{-}$,

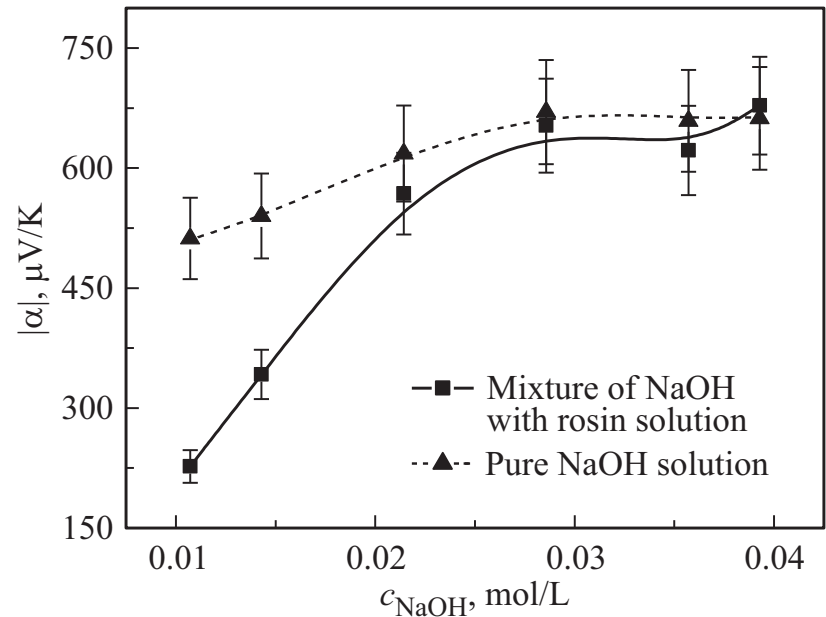

Рис. 2. Зависимость модуля коэффициента термоэдс растворов $\mathrm{NaOH}$ и его смеси с $2 \%$ коллоидным раствором канифоли от объемного содержания $\mathrm{NaOH}$. Коэффициент термоэлектрической силы $2 \%$ коллоидного раствора канифоли в дистиллированной воде составляет $\alpha=-53 \pm 8$ мкВ/K.

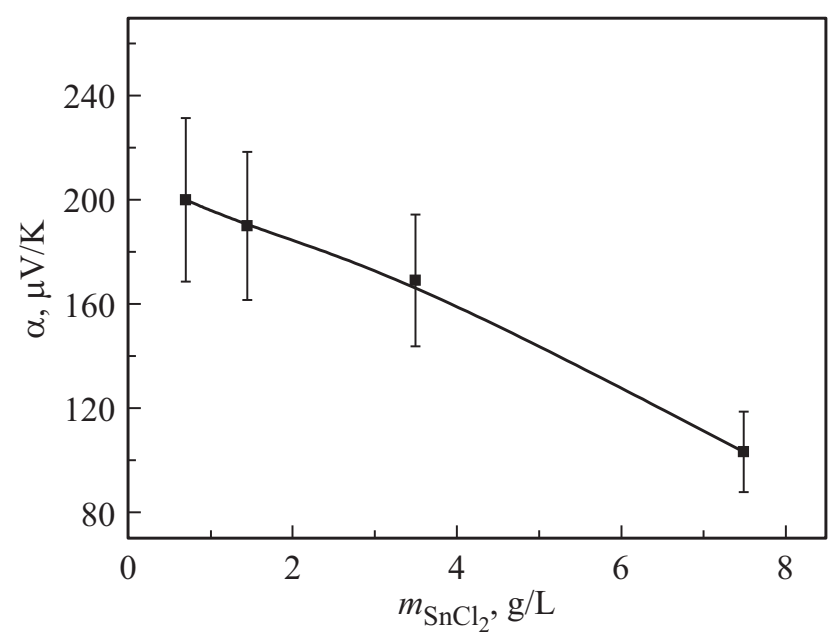

Рис. 3. Зависимость коэффициента термоэдс смеси растворов $\mathrm{SnCl}_{2}$ и танина в зависимости от массового содержания танина. Концентрация $\mathrm{SnCl}_{2} 0.001$ моль/л фиксирована. Коэффициент термоэлектрической эдс раствора хлорида олова (II) указанной концентрации $\alpha=+180 \pm 20$ мкВ/K.

поэтому в растворе присутствовало также небольшое количество не прореагировавшего иодида калия.

На рис. 4 показана зависимость коэффициента термоэдс коллоидных растворов AgI от их коэффициента электропроводности. Тип данной зависимости выбран в связи с тем, что в ходе диализной очистки электропроводность коллоидного раствора падает и, очевидно, является функцией концентрации ионного электролита, которая также уменьшается в ходе очистки.

Также на рис. 4 приведена зависимость для беспримесного ионного электролита $\mathrm{KNO}_{3}$, у которого при уменьшении концентрации соответствующим образом падает коэффициент электропроводности. Как видно 


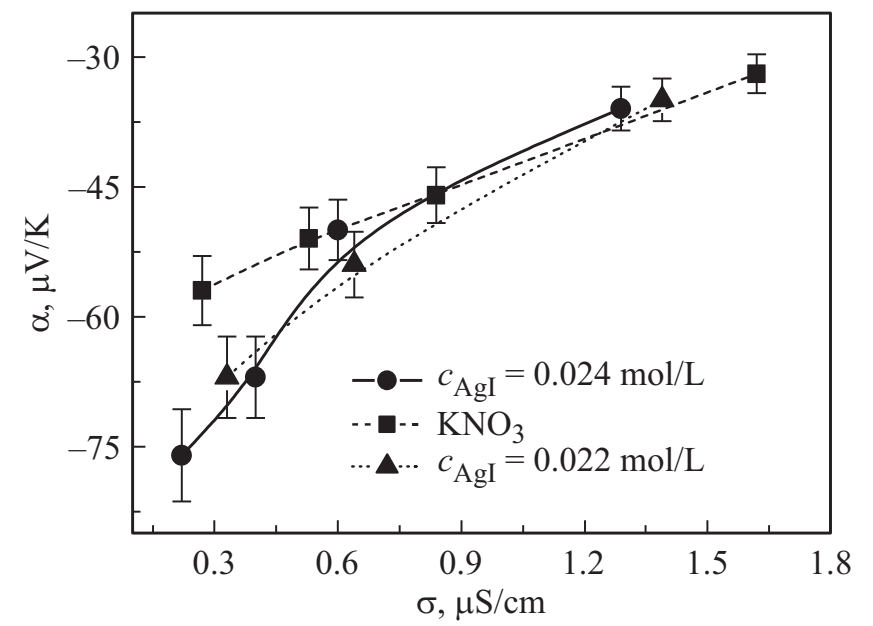

Рис. 4. Зависимость коэффициента термоэлектрической эдс от коэффициента электропроводности для коллоидных растворов $\mathrm{AgI}$ и беспримесного раствора $\mathrm{KNO}_{3}$. Зависимости для коллоидных растворов получены в процессе их диализной очистки.

из графиков, в исходном коллоидном растворе коэффициент термоэдс совпадает в пределах погрешности эксперимента с коэффициентом термоэдс раствора нитрата калия той концентрации, которая присутствует в коллоидном растворе.

В процессе диализной очистки коэффициент термоэдс коллоидного раствора растет по абсолютному значению, в то время как его электропроводность падает. Аналогичная закономерность в поведении коэффициента термоэдс наблюдается и для беспримесного раствора нитрата калия при уменьшении его концентрации. Однако в коллоидном растворе наблюдается более значительное увеличение коэффициента термоэлектрической силы по модулю, чем в ионном электролите. Поэтому увеличение коэффициента термоэдс коллоидного раствора не может быть объяснено лишь эффектом увеличения коэффициента термоэдс ионного электролита при уменьшении его концентрации. Очевидно, помимо данного вклада увеличение термоэлектрической силы коллоидного раствора может быть также обусловлено увеличением парциального вклада в термоэдс от коллоидных частиц иодида серебра.

Таким образом, полученные результаты подтверждают ранее высказанные предположения о вкладе свободных ионов и коллоидных частиц в итоговую величину термоэдс коллоидных растворов, следующие из анализа экспериментальных результатов для смесей коллоидных растворов и ионных электролитов.

Как показали дальнейшие эксперименты, увеличение коэффициента термоэлектрической эдс коллоидного раствора в результате его диализной очистки может быть значительным, как, например, это наблюдалось в коллоидном растворе $\mathrm{La}(\mathrm{OH})_{3}$, полученном в результате реакции двойного обмена $\mathrm{LaCl}_{3}+\mathrm{NaOH}=$ $=\mathrm{La}(\mathrm{OH})_{3}+3 \mathrm{NaCl}$. Данная реакция была проведена при значительном избытке хлорида лантана. В результате получился коллоидный раствор $\mathrm{La}(\mathrm{OH})_{3}$ концентрацией $c=1.2 \cdot 10^{-4}$ моль/л в присутствии смеси солей $\mathrm{LaCl}_{3}$ концентрацией $c=11.5 \cdot 10^{-4}$ моль/л и $\mathrm{NaCl}$ концентрацией $c=3.5 \cdot 10^{-4}$ моль/л. Коэффициент термоэдс исходного коллоидного раствора совпадал с термоэдс беспримесного ионного раствора $\mathrm{LaCl}_{3}$, который там присутствовал в подавляющем количестве и составлял $\alpha_{0}=-17 \pm 5$ мкв $/$ К. Коэффициент электропроводности был равен $\sigma=2.02$ мкСм/см. Далее проводилась многоступенчатая процедура диализной очистки, в конце которой электропроводность очищаемого раствора уменьшилась до $\sigma=0.07$ мкСм/см, а коэффициент термоэлектрической силы вырос до $\alpha_{0}=-182$ мкв $/ \mathrm{K}$, в то время как коэффициент термоэдс беспримесного водного раствора хлорида лантана, имеющего ту же электропроводность, что и коллоидный раствор, составлял $\alpha_{0}=-55$ мкв/К.

\section{4. Заключение}

Таким образом, на основе вышеизложенного можно сделать следующие выводы.

1. Гомогенная часть разности термоэлектрических потенциалов в растворах ионных электролитов определяется заряженными частицами раствора, имеющими самую высокую по абсолютному значению величину фактора $\alpha_{0 k}=\frac{\tau_{k} Q_{k}^{*}}{T}$, который зависит от теплоты переноса $Q_{k}^{*}$, вклада в электропроводность всего раствора $\tau_{k}$ (число переноса) и может быть назван парциальной термоэдс соответствующих частиц.

2. В коллоидных растворах, в которых крупные коллоидные частицы, несущие заряд за счет адсорбированных ими ионов, находятся совместно со свободными ионами, коэффициент термоэлектрической эдс растворов значительной электропроводности определяется ионной подсистемой в виду превышения парциальной термоэдс $\alpha_{0 k}$ для ионов по сравнению с коллоидными частицами. Это обусловлено подавляющим вкладом мелких, подвижных ионов в электропроводность коллоидного раствора по сравнению с коллоидными частицами [13] и их высокими значениями чисел переноса.

3. По мере уменышения относительного вклада ионов в электропроводность коллоидных растворов по сравнению с коллоидными частицами (например, за счет диализной очистки) парциальные термоэдс коллоидных частиц начинают превышать аналогичные значения для ионов. В этом пределе коэффициент термоэлектрической эдс коллоидных растворов начинает определяться коллоидными частицами, а не свободными ионами.

\section{Финансирование}

Исследование выполнено при финансовой поддержке РФФИ и администрации Липецкой области в рамках научного проекта 19-42-480001 и государственного задания Министерства просвещения России (проект FSZN-2020-0026). 


\section{Конфликт интересов}

Авторы заявляют, что у них нет конфликта интересов.

\section{Список литературы}

[1] Л.И. Анатычук Термоэлементы и термоэлектрические устройства (Киев, Наук. думка, 1979).

[2] Н.А. Измайлов Электрохимия растворов (М., Химия, 1974).

[3] P.F. Salazar, S. Kumar, B.A. Cola. Appl. Electrochem., 8, 325 (2014).

[4] T.J. Salez, B.T. Huang, M. Rietjens, M. Bonetti, C. WiertelGasquet, M. Roger, C.L. Filomeno, E. Dubois, R. Perzynski, S. Nakamae. Phys. Chem. Chem. Phys., 14, 19 (2017).

[5] M.F. Dupont., D.R. MacFarlane, J. M. Pringle. Chem. Commun., 53, 47 (2017).

[6] Р. Хаазе. Термодинамика необратимых процессов (М., Мир, 1967).

[7] J. Lenglet, A. Bourdon, J.C. Bacri, G. Demouchy. Phys. Rev. E, 65, 031408 (2002).

[8] R. Piazza, A. Parola. J. Phys. Condens. Matter, 20, 153102 (2008).

[9] А.В. Сидоров, В.М. Грабов, А.А. Зайцев, Д.В. Кузнецов. ФТП, 53 (6), 765 (2019).

[10] А.В. Сидоров, А.А. Зайцев, Д.В. Кузнецов. Междунар. науч.-исслед. журн., 7, 42 (2021).

[11] А.В. Сидоров, В.М. Грабов, А.А. Зайцев, Д.В. Кузнецов. ЖТФ, 90 (10), 1650 (2020).

[12] С.С. Воюцкий. Курс коллоидной химии (М., Химия, 1974).

[13] С.С. Духин. Электропроводность и электрокинетические свойства коллоидных систем (Киев, Наук. думка, 1975).

Редактор А.Н. Смирнов

\section{Influence of the ionic subsystem on the thermoelectric effect in colloidal solutions}

A.V. Sidorov' ${ }^{1}$, V.M. Grabov' ${ }^{2}$, A.A. Zaitsev' ${ }^{1}$, D.V. Kuznetsov ${ }^{1}$

${ }^{1}$ Bunin State University, 399770 Yelets, Russia

${ }^{2}$ Herzen State Pedagogical University of Russia, 191186 St. Petersburg, Russia

Abstract The thermoelectric effect is investigated in mixtures of colloidal solutions with ionic electrolytes in the initial state, when the formation of concentration gradients under the influence of an inhomogeneous temperature field can be neglected. Based on experimental measurements in mixtures with different concentrations of colloidal particles and ions, the conditions under with the coefficient of thermoelectric EMF is determined by the ion subsystem and under which the main contribution to the value of the thermoelectric force is made by colloidal particles are determined. 